\title{
Factors Associated with the Acceptance of Immediate Antiretroviral Therapy after HIV Diagnosis in Thai Cohort
}

Waraporn Kingkaew ${ }^{1,2}$, Buranee Kanchanatawan ${ }^{2}$, Nipat Teeratakulpisarn ${ }^{1}$, Deondara Trachunthong ${ }^{1,3}$, Prapaipan Plodgratoke $^{1}$, Chanjiraporn Pondet ${ }^{1}$, Chanin Suksom ${ }^{1}$, Siriporn Noennoy ${ }^{1}$, Somsong Teeratakulpisarn ${ }^{1}$, Nittaya Phanuphak ${ }^{1}$ and Praphan Phanuphak ${ }^{1,3}$

1. The Thai Red Cross AIDS Research Centre, Bangkok 10330, Thailand

2. Department of Psychiatry, Faculty of Medicine, Chulalongkorn University, Bangkok 10330, Thailand

3. The HIV Netherlands Australia Thailand Research Collaboration (HIV-NAT), Bangkok 10330, Thailand

\begin{abstract}
BACKGROUND: Since 2014, Thailand has recommend initiation of antiretroviral therapy (ART) immediately after HIV diagnosis, regardless of CD4 count. HIV treatment can prevent illnesses and deaths, avert new infections, and save costs. Achieving UNAIDS 90-90-90 targets by 2020 will enable Thailand to end the AIDS epidemic by 2030. Therefore, patients immediate consent to treatment to immediate ART treatment in people recently diagnosed with HIV are key to successful ART initiation and long-term adherence. We studied factors associated with acceptance of ART initiation among Thai people promptly after their HIV diagnoses. OBJECTIVES: To examine the prevalence and associated factors of consent to immediate initiation of antiretroviral therapy after HIV diagnosis among HIV-positive Thai patients. DESIGN: A cross-sectional descriptive study. SETTING: Anonymous Clinic, Thai Red Cross AIDS Research Centre. MATERIAL AND METHODS: This research is combination of quantitative and qualitative cross-sectional data collected for the purpose of identifying acceptance levels and associated factors with the initiation of ART treatment among people infected. A total of 216 participants were included in the study. Self-administered questionnaire and in-depth interviews were used to collect data from clients $\geq 18$ years. Binary logistic regression was performed to assess factors related to immediate ART acceptance. RESULTS: Enrollment of participants was 216 and $95.40 \%$ indicating they were prepared to start ART immediately and had demonstrated acceptance of their condition and $4.60 \%$ chose to defer. $61 \%$ were men who have sex with men, $31 \%$ were heterosexual, $2 \%$ were transgender women and $6 \%$ were bisexual men. Median (IQR) age was 29 (24-36) years; median (IQR) CD4 count was 274 (168-396) cells per cubic millimeter. 72\% had unprotected sex over the past 6 months, and 9\% had HIV-associated symptoms/AIDS-defining illness. Median (IQR) HIV knowledge score was 12 out of 15 (11-13.5), 74\% were aware of possible adverse health outcomes and $85 \%$ knew about resistance development as a result of poor ART adherence. Multivariable analysis showed that education equal or higher than bachelor's degree increased acceptance of immediate ART initiation (aOR 0.71, 95\%CI $0.008-0.645, P=0.01$ ). Having STI (aOR 7.822, 95\%CI 1.374-44.534, $P=0.02$ ) and obligation $(\mathrm{aOR} 0.157,95 \% \mathrm{CI}$ $0.032-0.770, P=0.02$ ) were significantly associated with ART acceptance. CONCLUSION: Acceptance of immediate ART after HIV diagnosis was very high among newly diagnosed HIV-positive clients at the Thai Red Cross Anonymous Clinic. Education, experience of STI and obligation consequences influenced ART acceptance.
\end{abstract}

Key words: Acceptance of ART, HIV-positive.

\section{Introduction}

Since 2014, Thailand has recommended antiretroviral therapy (ART) immediately after HIV diagnosis, regardless of CD4 count [1-3]. HIV treatment can prevent illnesses and deaths, avert new

Corresponding author: Waraporn Kingkaew, M.Sc., RN, research field: HIV/AIDS. infections, and save costs $[4,5]$. The quality of life of people living with HIV/AIDS has improved drastically with the introduction of antiretroviral therapy (ART), resulting in viral suppression and CD4 count recovery among treatment-naive patients [6]. However, access to ART is still uneven, and can vary based on public policies and treatment costs in each country $[4,7]$.

In INSIGHT START Study Group, initiation of 
antiretroviral therapy in early asymptomatic HIV infection [8] involving previously untreated HIV-positive adults with a CD4 count of more than 500 cells $/ \mathrm{mm}^{3}$ demonstrated immediate initiation of ART was superior to deferral until the CD4 count declined to 350 cells $/ \mathrm{mm}^{3}$. A decline in both serious AIDS-related and serious non-AIDS-related events was found, and no increased rate of adverse effects associated with this strategy were observed.

The Sub-Saharan Africa TEMPRANO Trial [9] recruited 2,056 HIV-infected adults who, under WHO guidelines of time were not eligible to start ART, in which Isoniazid preventive therapy is not recommended. Participants had baseline CD4 counts evenly distributed on both sides of the CD4 threshold of 500 cells $/ \mathrm{mm}^{3}$. The early initiation of ART and six months of IPT independently resulted in a $44 \%$ lower HIV-related illnesses and a 35\% lower risk of death from any cause.

Moreover, ART reduces viral replication limiting the transmission of HIV in sero-discordant couples. In HPTN 052 study [10], 1,763 couples were enrolled from nine countries with African couples constituting $54 \%$ of the total recruited, and $50 \%$ of those couples were male. These figures correspond with the findings of PARTNER study interim [11] and besides that no episodes of transmission among 16,400 episodes of anal sex were found (including condom-protected ones) in gay men. The Opposite Attract study [12], has started recruiting participants who were gay male sero-different couples regardless of whether the HIV-positive partner is on antiretroviral therapy (ART) or has an undetectable viral load, and also regardless of whether condoms use or not since May 2012. It is now recruiting not only in the three Australian cities (Sydney, Brisbane and Melbourne) but also in Cairns, Australia and in Bangkok, Thailand and Rio de Janeiro, Brazil since the year 2014. Whether transmissions are linked or not is determined by genetically testing the HIV of any study participant who becomes newly infected to see if it closely resembles their regular partner's virus. No transmissions between couples (linked transmission) have so far been seen in Opposites Attract study.

Thailand has implemented guidelines to recommend initiation of antiretroviral therapy (ART) immediately after HIV diagnosis in people infected with HIV regardless of CD4 since 2014. The combined effort of patients and civil society groups to guarantee the right of all individuals with HIV/AIDS to receive the drugs free of charge is necessary for their treatment [13]. The high cost of antiretroviral therapies and the growing number of patients in need of ART have been a continuing challenge for the Ministry of Health. Thailand has adopted several strategies to reduce the cost of ART, including local production of drugs to provide drugs at lower cost. As a result, the government has been able to maintain its commitment despite increased number of patients under treatment and increased proportion of them who require more expensive and complex treatment schemes [14]. Universal distribution of ARV drugs has resulted in an improved quality of life for patients, as well as increased survival and a significant reduction in hospitalizations [15-17].

The public health system provides all necessary laboratory tests for HIV diagnosis and patient follow-up [1]. In recent years, Thai public health policies have been implemented to encourage periodic HIV testing amongst the general population. For example, HIV testing has become a routine part of general care.

The policy of treating HIV-infected people according to Thailand National AIDS Strategic Treatment Guideline 2014 and the World Health Organization (WHO) 2015 [4] concur in that HIV-infected individuals should receive antiretroviral drugs to all levels of CD4 immune in order to reduce illness and disease complications. Achieving UNAIDS 90-90-90 [15] targets by 2020 will enable Thailand to end the AIDS epidemic by 2030 . Willingness and readiness to immediate ART of people 
recently diagnosed with HIV are the keys to successful ART initiation and long-term adherence. We studied factors associated with acceptance of ART initiation among Thai people immediately post HIV diagnosis.

\section{Methods}

This research is a combination of quantitative and qualitative cross-sectional study. The data were collected for the purpose of identifying acceptance of ART levels and associated factors with initiation of ART treatment among HIV infected patients. Self-administered questionnaire and interview were used to collect data from clients aged $\geq 18$ years at the Thai Red Cross Anonymous Clinic, which is the largest HIV testing and counseling center in the Thai region. HIV screened participants who received HIV-positive test results were consecutively enrolled between July to December 2015. Demographic data, HIV knowledge, acceptance of immediate ART, incentives and barriers towards ART acceptance were assessed. Binary logistic regression was performed to assess factors related to immediate ART acceptance.

\subsection{Measurement}

Tools used in this research included a self-administered questionnaire, and the interviews by researchers. Questionnaire is divided into three parts:

Part 1. Self-administered questionnaire is composed of basic information including demographic data e.g. age, gender, marital status, religion, occupation, income, education, age at first sexual intercourse, condom use pattern, physical illness, psychiatric diseases and sexually transmitted infection. Risk factors for HIV infection and decision of starting antiretroviral therapy were also included in the questionnaire.

Part 2. Interview focusing on questions surrounding present disease state i.e. CD4 count, HIV-associated symptoms/AIDS-defining illnesses and current medications.
Part 3. Self-administered questionnaires composed of knowledge base of HIV as well as experience with, Post-exposure prophylaxis treatment, Pre-exposure prophylaxis. Self-preparation for ART initiation anxiety to treatment was measured utilizing the Patient Health Questionnaire -9 (PHQ-9).

The patients getting start ART within 2 weeks after diagnosis, with median days between seven days and 14 days at the Thai Red Cross Anonymous Clinic or other referral center. CD4 and viral load were done to all patients at the Thai Red Cross Anonymous Clinic at the same day of HIV infected diagnosis before start ART, respectively reducing the effect of this potential bias and prevent loss to follow-up, patients would asked to return receive CD4 and viral load result within 7 days.

\section{Results}

216 participants, $95.4 \%$ indicated immediate ART acceptance and $4.6 \%$ refused (would like to defer) ART (Fig. 1).

Between July to December 2015, 216 participants, 95.4\% indicated immediate ART acceptance and 4.6\% deferred ART. The main exposure to HIV was through intercourse with $61 \%$ men who have sex with men, $31 \%$ heterosexual, $2 \%$ transgender women and $6 \%$ bisexual men. Median age was 29 (24-36, [interquartile range (IQR)]) years, median (IQR) CD4 count was 274 (168-396) cells $/ \mathrm{mm}^{3}$. Seventy two percent had unprotected sex over the past 6 months, and 9\% reported a HIV-associated symptoms/AIDS-defining illness. Median (IQR) HIV knowledge score was 12 out of 15 (11-13.5), 74\% were aware of possible adverse health outcomes and $85 \%$ knew about resistance development as a result of poor ART adherence (Table 1).

Table 2 shows immediate ART acceptance and associated factors after HIV diagnosis. Education attainment is associated with ART acceptance $P=0.01$, $48.54 \%$ graduated bachelor degree, subsequently with $41.26 \%$ education lower than bachelor degree. 


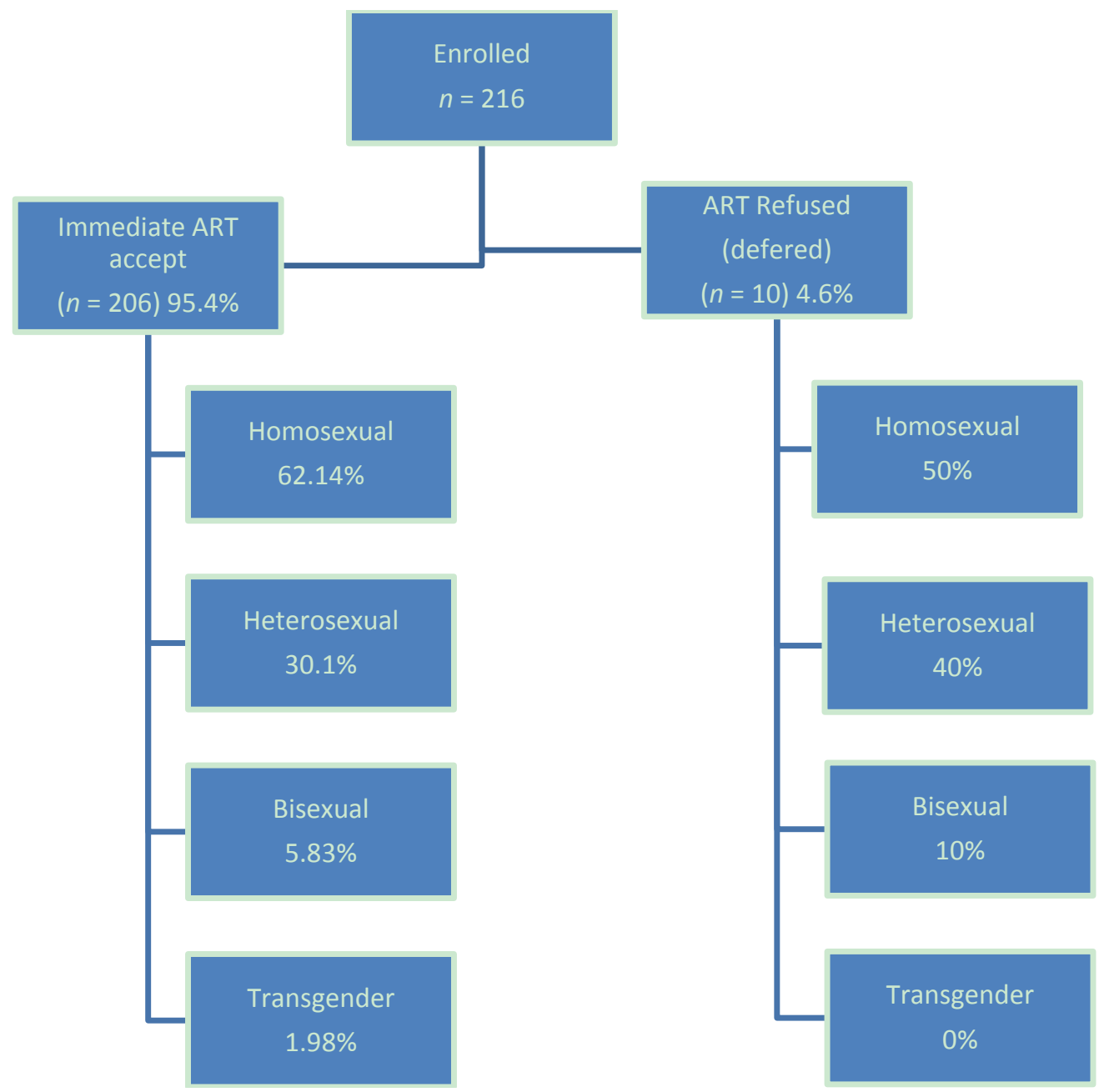

Fig. 1 Data diagram of the study, participants had acceptance and refusal ART divided by group.

Table 1 Characteristics acceptance of immediate antiretroviral therapy after HIV diagnosis.

\begin{tabular}{lll}
\hline Characteristics & $\mathrm{N}$ & $\%$ \\
\hline Sex & & 15.74 \\
\hline Female & 182 & 84.26 \\
$\quad$ Male & & \\
\hline Gender identity & 133 & 61 \\
\hline Homosexual / MSM & 66 & 31 \\
Heterosexual & 4 & 2 \\
Transgender women & 13 & 6 \\
Bisexual & & \\
\hline Age $\quad$ & & \\
\hline IQR =29 (24-36) & & \\
\hline Education & & \\
\hline Uneducated & 93 & 3.70 \\
Lower than Bachelor degree & 101 & 43.06 \\
$\quad$ Bachelor degree & 14 & 46.76 \\
$\quad$ Higher than Bachelor degree & & 6.48 \\
\hline
\end{tabular}


(table 1 continued)

\begin{tabular}{|c|c|c|}
\hline Characteristics & $\mathrm{N}$ & $\%$ \\
\hline \multicolumn{3}{|l|}{ Occupation } \\
\hline Unemployed & 12 & 5.56 \\
\hline Student & 39 & 18.06 \\
\hline Government service & 11 & 5.09 \\
\hline Business owner & 37 & 17.13 \\
\hline Employee & 109 & 50.46 \\
\hline Sex worker & 4 & 1.85 \\
\hline Other not specify & 4 & 1.85 \\
\hline \multicolumn{3}{|l|}{ Age of first sexual intercourse } \\
\hline \multicolumn{3}{|l|}{$\mathrm{IQR}=18(16-20)$} \\
\hline \multicolumn{3}{|l|}{ Condom use within the last 6 months } \\
\hline Always & 60 & 27.78 \\
\hline Sometime & 117 & 54.17 \\
\hline Never & 39 & 18.06 \\
\hline \multicolumn{3}{|l|}{ CD4 count (cells/mm³) } \\
\hline \multicolumn{3}{|l|}{$\mathrm{IQR}=274(168-396)$} \\
\hline HIV-associated symptoms/AIDS-defining illnesses & 20 & 9.26 \\
\hline \multicolumn{3}{|l|}{ HIV knowledge score } \\
\hline \multicolumn{3}{|l|}{$\mathrm{IQR}=12$ out of $15(11-13.5)$} \\
\hline Aware of poor ART adherence cause adverse health outcomes & 161 & 74.54 \\
\hline Aware of poor ART adherence cause knew about resistance development & 183 & 84.72 \\
\hline \multicolumn{3}{|l|}{ Decision to start ART } \\
\hline Yes & 206 & 95.37 \\
\hline No & 10 & 4.63 \\
\hline
\end{tabular}

Table 2 Univariate Analysis and Associated factors with acceptance of immediate antiretroviral therapy.

\begin{tabular}{|c|c|c|c|}
\hline \multirow[b]{2}{*}{ Factors } & \multicolumn{2}{|c|}{$N=216$} & \multirow[t]{2}{*}{$P$-value } \\
\hline & $\begin{array}{l}\text { ART } \\
\text { Acceptance } \\
(n=206)\end{array}$ & $\begin{array}{l}\text { ART } \\
\text { Refusal } \\
(n=10)\end{array}$ & \\
\hline Sex & & & $>0.99$ \\
\hline Male & $175(84.95)$ & $7(70)$ & \\
\hline Female & $31(15.05)$ & $3(30)$ & \\
\hline Education $(n, \%)$ & & & $0.01^{*}$ \\
\hline Uneducated & $7(3.40)$ & $1(10)$ & \\
\hline Lower than Bachelor degree & $85(41.26)$ & $8(80)$ & \\
\hline Bachelor degree & $100(48.54)$ & $1(10)$ & \\
\hline Higher than Bachelor degree & $14(6.80)$ & $0(0)$ & \\
\hline $\begin{array}{l}\left.\text { CD4 count (cells } / \mathrm{mm}^{3}\right) \\
\text { Median (IQR) } 274(168-396)\end{array}$ & & & 0.18 \\
\hline$<350$ & $122(59.22)$ & $3(30)$ & \\
\hline $350-500$ & $55(26.22)$ & $4(40)$ & \\
\hline$>500$ & $29(14.08)$ & $3(30)$ & \\
\hline Any STI with in the last one year & $36(17.48)$ & $4(40)$ & 0.09 \\
\hline HIV related illnesses $(n, \%)$ & & & 0.23 \\
\hline No & $188(81.26)$ & $8(80)$ & \\
\hline Yes & $18(8.74)$ & $2(20)$ & \\
\hline
\end{tabular}


(table 2 continued)

\begin{tabular}{|c|c|c|c|}
\hline \multirow[b]{2}{*}{ Factors } & \multicolumn{2}{|c|}{$N=216$} & \multirow[t]{2}{*}{$P$-value } \\
\hline & $\begin{array}{l}\text { ART } \\
\text { Acceptance } \\
(n=206)\end{array}$ & $\begin{array}{l}\text { ART } \\
\text { Refusal } \\
(n=10)\end{array}$ & \\
\hline \multicolumn{4}{|c|}{ Something that need to responsible e.g., take care of children, take care of parents, etc. } \\
\hline Yes & $157(76.21)$ & $5(50)$ & 0.13 \\
\hline No & $49(23.79)$ & $5(50)$ & \\
\hline Aware of poor ART adherence cause adverse health outcomes & & & $0.02^{*}$ \\
\hline Yes & $157(76.21)$ & $4(40)$ & \\
\hline No & $49(23.79)$ & $6(60)$ & \\
\hline Aware of poor ART adherence cause ART resistance development & & & $0.04 *$ \\
\hline Yes & $177(85.92)$ & $6(60)$ & \\
\hline No & $29(14.08)$ & $4(40)$ & \\
\hline Depression score (PHQ-9)** & & & 0.21 \\
\hline No symptoms $(0-4)$ & $70(33.98)$ & $4(40)$ & \\
\hline Not to mild (5-8) & $69(33.50)$ & $5(50)$ & \\
\hline Mild (9-14) & $45(21.84)$ & $1(10)$ & \\
\hline Moderate (15-19) & $10(4.85)$ & $0(0)$ & \\
\hline Severe $(20+)$ & $12(5.83)$ & $0(0)$ & \\
\hline
\end{tabular}

** Patients Health Questionnaire-9 [18].

$* P \leq 0.05$.

Table 3 Multiple Logistic Regression to predict associated factors with acceptance of immediate antiretroviral therapy after HIV diagnosis.

\begin{tabular}{|c|c|c|c|}
\hline Associated factors to ART acceptance & Adjusted OR & $95 \% \mathrm{CI}$ & $P$ value \\
\hline \multicolumn{4}{|l|}{ Sex } \\
\hline Female & 1 & & \\
\hline Male & 0.168 & $0.027-1.055$ & $0.05^{*}$ \\
\hline \multicolumn{4}{|l|}{ Education } \\
\hline Lower than Bachelor degree & 1 & & \\
\hline Higher or equal Bachelor degree & 0.071 & $0.008-0.645$ & $0.01 *$ \\
\hline \multicolumn{4}{|l|}{ Any STI with in the last one year } \\
\hline No & 1 & & \\
\hline Yes & 7.822 & $1.374-44.534$ & $0.02 *$ \\
\hline \multicolumn{4}{|l|}{ HIV related illnesses within last 3 months } \\
\hline No & 1 & & \\
\hline Yes & 6.422 & $0.878-46.984$ & 0.06 \\
\hline \multicolumn{4}{|c|}{ Something that need to responsible e.g., take care of children, take care of parents, etc. } \\
\hline No & 1 & & \\
\hline Yes & 0.157 & $0.032-0.770$ & $0.02 *$ \\
\hline \multicolumn{4}{|l|}{ Depression score (PHQ-9) } \\
\hline No & 1 & & \\
\hline Yes & 0.132 & $0.013-1.311$ & 0.08 \\
\hline
\end{tabular}

$* P \leq 0.05$.

To demonstrate how ART adherence awareness was associated with ART acceptance, $76.21 \%$ of the subjects were aware that poor ART adherence could produce adverse health outcomes $P=0.02$, and $85.92 \%$ of the subjects were also aware that poor ART adherence could be a cause of ART resistance development, which was significantly associated with ART acceptance $P=0.04$. 
The multivariate analysis showed that education equal or higher than bachelor's degree (OR 0.071, 95\%CI 0.008-0.645, $P=0.01$ ), history of STI (OR $7.822,95 \%$ CI $1.374-44.534, P=0.02$ ) and obligation such as responsibilities to family or work were associated with ART acceptance (OR 0.157, 95\% CI $0.032-0.770, P=0.02)$. In addition, male participants (OR 0.168, 95\%CI 0.027-1.055, $P=0.05$ ) were significantly associated with higher level of ART acceptance.

\section{Discussion}

Overall we enrolled 216 participants. $62 \%$ were MSM, median age was $(\mathrm{IQR})=29(24-36)$ years, $53.24 \%$ were education in bachelor degree and $46.76 \%$ were education lower than bachelor degree. Median income per month was 15,000 (IQR = 13,000-25,000). Median age of first time sexual intercourse was 18 (IQR = 16-20) years, HIV infected risk factor was being sexual intercourse without condom (72.23\%) and $95.37 \%$ accept ART after HIV diagnosis. We found significant associated factors ART acceptance were education (aOR 0.071, 95\%CI 0.008-0.645, $P=0.01$ ), STIs (aOR 7.822, 95\%CI 1.374-44.534, $P=0.02$ ), obligation (aOR 0.157, 95\%CI 0.032-0.770, $P=0.02$ ) and male gender (aOR 0.168, 95\%CI 0.027-1.055, $P=0.05$ ). However, most of study participants were MSM. Our results were not similar with previous study from Malawi, southeastern Africa [7], where the most significant predictors of starting ART among HIV infected patients base on WHO stage 3-4 and living 2.5-5 km from the clinic increased ART initiation. More recently in South Africa, having a regular partner was found to be factor associated with ART initiation [7]. Studies from Uganda [19] and Malawi [20] suggest that ART uptake is influenced by patient acceptance of their HIV-positive status, disclosure, and preparation for ART initiation. These differences may be due to socioeconomic factors and ART guidelines that are inherent to each country. ART immediate initiation is recommend for everyone infected with HIV [2]. It's especially important to start ART right away in patients who present pregnant, with AIDS, certain HIV-related illnesses and co-infections, and early HIV infection (defined as HIV infection within 6 months from time of exposure).

Firstly, we found education level is the principal factor associated with ART initiation at the Thai Red Cross Anonymous Clinic. Increasing the effect of ART counseling preparedness may influence ART initiation. However, our finding that education increases the likelihood of ART initiation is consistent with regional findings on the individual and service-level factors that influence patient during counseling period. Studies from Ethiopia [21], Uganda [22], rural Malawi and Zimbabwe [23] suggest that ART uptake is influenced by patient acceptance of their HIV-positive status, disclosure, and preparation for ART initiation. Among healthcare factors, patients from a South African clinic who returned for one or more routine HIV counseling visits and had multiple exposures to health care providers appeared to increase patient motivation and reject common myths about ART reducing delays in ART initiation [24].

Secondly, sexual transmitted disease was another significant factor to ART initiation. In this research finding, most of participants have been multiple partners and sexually active without condom. Other studies from the region $[25,26]$ have noted that STD associated with ART acceptance. Readiness and willingness with aware ART treatment combined with preparation to start lifelong ART were influencing ART initiation. We found that HIV-related illness increased the odds of starting ART. Although the Thai Red Cross Anonymous Clinic provides STI treatment, a stronger, positive effect of STI co-infection at eligibility on ART initiation was evident and purposefully integrated into the services offered at the TRCARC. Possibly, sicker patients with easy access to comprehensive STI care may be more likely to initiate ART, suggesting an additional benefit of service integration [1]. 
However, our finding is different from the study in Africa [27] in that socio-economic factors (obligations) are likely contribute to ART acceptance among Thai HIV-positive patients who are employed. In Africa, on the contrary, adult men are the significant variables.

There are limitations to this study. First, patients at TRCARC were well educated with at least a bachelor degree, and patients were aware of the importance of early ART acceptance; most patients were employed and had good income. However, some participants deferred to seek care at the government clinic/hospital where treatment is covered. Second, the number of multiple visits at the Thai Red Cross Anonymous Clinic is not stored. Therefore, the number and type of visits between initial registration and HIV counseling cannot be determined, decreasing our ability to determine the service factors and the frequency of visits to HIV counseling that may be influential during that period. In addition, regarding the strengths of this study, TRCARC is a large, well-established urban center offering a full package of services with ART initiation. This will be a good opportunity for other Thais in rural area for HIV naïve patients to start ART.

\section{Conclusion}

Acceptance of immediate ART after HIV diagnosis was very high among newly diagnosed HIV-positive clients at the TRCARC. High education level, experience of STIs and a sense of obligation were associated with ART initiation. The findings suggest several steps that can be taken to respond to the needs of most at risk populations that may have barriers to accepting ART [21]. Clinics need to offer STI screening services along with HIV related services as it may address systematic weaknesses in some communities.

\section{Acknowledgment}

We would like to express our sincere thanks to all participants. Tanya Do PhD, Dr.Win Min Han, Dr. Vorapot Sapsirisavat, Supalak Phonphithak and
Funding for this project was supported in part by National Research Council of Thailand (NRCT 2016).

\section{References}

[1] Phanuphak, N., Chamnan, P., Pathipvanich, P., Thongpaen, S., Nonenoy, S., Jantarapakde, J, Pengnonyang, S., Teeratakulpisarn, N., Kongkabpan, M., Jitrach, K., Pinyakorn, S., Sungsing, T., Naowajit, S., Parasate, K., Seneewong Na Ayutthaya, S., Chansiri, K., Poorisri, T., Lertpiriyasuwat, C., Akksilp S., and Phanuphak, P. 2014. "Factors Associated with Uptake of Immediate ART Regardless of CD4 Count among Thai MSM and TG in the Test and Treat Program." Presented at 20th International AIDS Conference, Melbourne, Australia.

[2] Phanuphak, N., Pattanachaiwit, S., Pankam, T., Pima, W., Avihingsanon, A., and Teeratakulpisarn, N. 2011. "Active Voluntary Counseling and Testing with Integrated CD4 Count Service can Enhance Early HIV Testing and Early CD4 Count Measurement: Experiences from the Thai Red Cross Anonymous Clinic in Bangkok, Thailand." $J$. Acquir. Immune Defic. Syndrom 56 (3): 244-52.

[3] Ruxrungtham, K., Chetchotisakd, P., and Anunnatsiri, S. 2014. "Thailand National Guidelines on HIV/AIDS Treatment and Prevention." Department of Disease Control Ministry Public Health.

[4] WHO. 2015. Guideline on When to Start Antiretroviral Therapy and on pre-Exposure Prophylaxis for HIV. WHO, Geneva, Switzerland.

[5] UNAIDS. 2014. "90-90-90 an Ambitious Treatment Target to Help End the AIDS Epidemic." UNAIDS, Geneva, Switzerland.

[6] Souza-Jr, P. R. B., Szwarcwald, C. L., and Castilho, E. A. 2007. "Delay in Introducing Antiretroviral Therapy in Patients Infected by HIV in Brazil." Clinics 62 (5): 579-84.

[7] Feldacker, C., Johnson, D., Hosseinipour, M., Phiri, S., and Tweya, H. 2012. "Who Starts? Factors Associated with Starting Antiretroviral Therapy among Eligible Patients in Two, Public HIV Clinics in Lilongwe, Malawi." PLoS ONE 7 (11): e50871.

[8] INSIGHT START Study Group. 2015. "Initiation of Antiretroviral Therapy in Early Asymptomatic HIV Infection.” N. Engl. J. Med. 373 (9): 795-807.

[9] TEMPRANO ANRS 12136 Study Group. 2015. “A Trial of Early Antiretrovirals and Isoniazid Preventive Therapy in Africa." N. Engl. J. Med. 373 (9): 808-22.

[10] Grinsztejn, B., Hosseinipour, M. C., Ribaudo, H. J., Swindells, S., Eron, J., Chen, Y. Q., Wang, L., Ou, S. S., Anderson, M., McCauley, M., Gamble, T., Kumarasamy, N., Hakim, J. G., Kumwenda, J., Pilotto, J. H., Godbole, S. 
V., Chariyalertsak, S., de Melo, M. G., Mayer, K. H., Eshleman, S. H., Piwowar-Manning, E., Makhema, J., Mills, L. A., Panchia, R., Sanne, I., Gallant, J., Hoffman, I., Taha, T. E., Nielsen-Saines, K., Celentano, D., Essex, M., Havlir, D., Cohen, M. S., HPTN 052-ACTG Study Team 2014. "Effects of Early Versus Delayed Initiation of Antiretroviral Treatment on Clinical Outcomes of HIV-1 Infection: Results from the Phase 3 HPTN 052 Randomised Controlled Trial." Lancet Infect. Dis. 14 (4): 264.

[11] Rodger, A. J., Cambiano, V., Bruun, T., Vernazza, P., Collins, S., van Lunzen, J., Corbelli, G. M., Estrada, V., Geretti, A. M., Beloukas, A., Asboe, D., Viciana, P., Gutiérrez, F., Clotet, B., Pradier, C., Gerstoft, J., Weber, R., Westling, K., Wandeler, G., Prins, J. M., Rieger, A., Stoeckle, M., Kümmerle, T., Bini, T., Ammassari, A., Gilson, R., Krznaric, I., Ristola, M., Zangerle, R., Handberg, P., Antela, A., Allan, S., Phillips, A. N., Lundgren, J., PARTNER Study Group. 2016. "Sexual Activity without Condoms and Risk of HIV Transmission in Serodifferent Couples When the HIV-Positive Partner Is Using Suppressive Antiretroviral Therapy.” JAMA 316 (2): $1-11$.

[12] Grulich, A., Benjamin, R. B., Fengyi, J., Garrett, P., Iryna, B. Z., Beatriz, G., Phanuphak, P., Richard, M., and Kersten, K. K. 2015. "HIV Transmission in Male Serodiscordant Couples in Australia, Thailand and Brazil." Presented at the 2015 Conference on Retroviruses and Opportunistic Infection (CROI), Seattle, USA.

[13] Teixeira, P. R., Vitória, M. A., Barcarolo, J. 2004. "Antiretroviral Treatment in Resource-Poor Settings: The Brazilian Experience.” AIDS 18 (suppl 3): S5-7.

[14] Levi, G. C., and Vitória, M. A. 2002. "Fighting Against AIDS the Brazilian Experience." AIDS 16 (18): 2373-83.

[15] Matida, L. H., and Marcopito, L. F. 2007. "Delay in Introducing Antiretroviral Therapy in Patients Infected by HIV in Brazil, 2003-2006." Clinics 62 (5): 579-84.

[16] Marins, J. R., Jamal, L. F., Chen, S. Y., Barros, M. B., Hudes, E. S., Barbosa, A. A., Chequer, P., Teixeira, P. R., and Hearst, N. 2003. "Dramatic Improvement in Survival among Adult Brazilian AIDS Patients." AIDS 17 (11): 1675-82.

[17] Murray, L. K., Semrau, K., McCurley, E., Thea, D. M., Scott, N., Mwiya, M., Kankasa, C., Bass, J., and Bolton, P. 2009. "Barriers to Acceptance and Adherence of Antiretroviral Therapy in Urban Zambian Women." AIDS Care 21 (1): 78-86.

[18] Lotrakul, M., Sumrithe, S., and Saipanish, R. 2008.
"Reliability and Validity of Thai Version of the PHQ-9." BMC Psychiatry 8: 46.

[19] Amuron, B., Namara, G., Birungi, J., Nabiryo, C., Levin, J., Grosskurth, H., Coutinho, A., and Jaffar, S. 2009. "Mortality and Loss-to-follow-up During the pre-Treatment Period in an Antiretroviral Therapy Programme under Normal Health Service Conditions in Uganda.” BMC Public Health 9: 290.

[20] McGuire, M., Munyenyembe, T., Szumilin, E., Heinzelmann, A., Le Paih M., Bouithy, N., and Pujades-Rodríguez, M. 2010. "Vital Status of pre-ART and ART Patients Defaulting from Care in Rural Malawi." Tropical Medicine \& International Health 15 (Suppl 1): 55-62.

[21] Degefa, A., Sanders, E. J., Mekonnen, Y. Messele, T., Wolday, D., Dorigo-Zetsma, W., Mekonnen, W., Schaap, A., and Dukers, N. H. 2003. "Knowledge and Attitudes towards Antiretroviral Therapy among Factory Workers Participating in a Cohort on HIV and AIDS, Addis Ababa, Ethiopia." Ethiopian Medical Journal 41 (Suppl 1): 75-87.

[22] Amuron, B., Namara, G., Birungi, J., Nabiryo, C., Levin, J., Grosskurth, H., Coutinho, A., and Jaffar, S. 2009. "Mortality and Loss-to-follow-up during the pre-Treatment Period in an Antiretroviral Therapy Programme under Normal Health Service Conditions in Uganda." BMC Public Health 9: 290.

[23] Rasschaert, F., Koole, O., Zachariah, R., Lynen, L., Manzi, M., and Van Damme, W. 2012. "Short and Long Term Retention in Antiretroviral Care in Health Facilities in Rural Malawi and Zimbabwe." BMC Public Health 12: 444.

[24] Jarvis, J. N., Meintjes, G., Wood, R., and Harrison, T. S. 2010. "Testing But Not Treating: Missed Opportunities and Lost Lives in the South African ART Programme." AIDS (London, England) 24 (8): 1233-5.

[25] Hayes, R., Watson-Jones, D., Celum, C., vande Wijgert, J., and Wasserheit, J. 2010. "Treatment of Sexually Transmitted Infections for HIV Prevention: End of the Road or New Beginning? AIDS 24 (suppl 4): S15-26.

[26] Wasserheit, J. N. 1992. "Epidemiological, Synergy. Interrelationships between Human Immunodeficiency Virus Infection and Other Sexually Transmitted Diseases." Sex Transm. Dis. 19 (2): 61-77.

[27] Pepper, D. J., Marais, S., Wilkinson, R. J., Bhaijee, F., De Azevedo V., and Meintjes, G. 2011. "Barriers to Initiation of Antiretrovirals During Antituberculosis Therapy in Africa." PLoS One 6 (5): e19484. 